\title{
Komposisi Takson Tingkat Suku Serangga yang Terperangkap dalam Kantong Nepenthes spp. di Taman Nasional Sebangau Kalimantan Tengah
}

\author{
Adventus Panda ${ }^{* *}$, Yohanes Edi Gunawan ${ }^{1)}$ \\ ${ }^{1)}$ Laboratorium Zoologi, Program Studi Pendidikan Biologi Fakultas Keguruan dan Ilmu Pengetahuan \\ Universitas Palangka Raya
}

Alamat korespondensi*: apanda@fkip.upr.ac.id

\begin{abstract}
ABSTRAK
Serangga merupakan ordo penting dalam kelas Arthropoda, karena serangga merupakan salah satuindikator keseimbangan dan kesehatan suatu ekosistem. Peran ekologis anggota ordo ini sangat penting, terutama dalam hal interaksi hewan-tumbuhan, termasuk hubungannya dengan manusia.Salah satu bentuk interaksi tersebut adalah tingkat tropik. Dalam konteks komunitas, tingkatan tropik juga terjadi dalam skala mikro, seperti pada Kantong Nepenthes spp.Nepenthes spp. Modifikasi daun serupa kantong pada Nepenthes spp. hanya dapat dijumpai tumbuh liar pada tanah yang miskin unsur hara, seperti pada tanah gambut di Kalimantan Tengah. Tujuan penelitian ini adalah mempelajari komposisi takson tingkat suku serangga yang terperangkap dalam kantung Nepenthes spp. Penelitian menggunakan teknik survey, dengan sistem jalur dikombinasikan dengan plot berpetak (transects with nested plot). Pengambilan data dilakukan di dua lokasi berbeda di Taman Nasional Sebangau, yakni kawasan Habaring Hurung (SPTN Wilayah I Kota Palangkaraya) pada Juli 2016, dan kawasan Eks. Kanal PT. Sanitra Sebangau Indah (SSI), yang merupakan wilayah SPTN Wilayah II Pulang Pisau, pada September 2016. Pemilihan lokasi didasarkan pada kelimpahan Nepenthes spp., perbedaan tipe habitat dan kemudahan aksesibillitasHasil pengambilan data berupa spesimen, dibawa ke laboratorium dan dilanjutkan dengan identifikasi sampai pada tingkat suku. Hasil penelitian menunjukkan takson tingkat suku serangga yang terperangkap dalam Kantong Nepenthes yang ditemukan selama penelitian di Resort Habaring Hurung, adalah sebanyak sembilan takson suku serangga. Sementara itu di area Kanal Eks PT. SSI Taman Nasional Sebangau menunjukkan delapan takson suku serangga. Takson suku yang secara konsisten dijumpai hampir di seluruh specimen kantung pada dua lokasi kajian adalah dari kelompok takson suku Formicidae (Semut), Culicidae (Nyamuk) dan Thormisidae (Laba-laba kepiting).
\end{abstract}

Kata Kunci :Takson Serangga, Habaring Hurung, Sanitra Sebangau Indah, Nepenthes spp., Taman Nasional Sebangau

\section{ABSTRACT}

Insects are an important order in the class of arthropods, used as an indicator of the balance and health of an ecosystem. The ecological roles of the order arevery important, especially in terms of animal-plant interactions, including its relationship with humans. Nepenthes spp. is a plant with a very high adaptive capacity. Similar modifications leaf can only be found growing wild in nutrient-poor soils, such as peatlandin Central Kalimantan. The purpose of this research is to study the composition of the insect's taxon trapped in the Nepenthes spp. The study used survey techniques, with a track system combined with terraced plots (transects with anested plot). Data wascollected in two different locations in Sebangau National Park, a region Habaring Hurung (SPTN Region I Palangkaraya) in July 2016, and the Ex area. Channel PT. Sanitra Sebangau Indah (SSI), which is a region SPTN Region II Pulang Pisau (inSeptember 2016). The specimenswas carried outto the laboratory, for further identification process. The results showed that taxon insects trapped in Nepenthes inHabaring Hurung, is nine families. Meanwhile,in SSI revealed eight families. Families' taxa that consistently found within two locations were Formicidae (Ants), Culicidae (mosquitoes) and Thormisidae (spider crab).

Keywords: Insect taxa, Habaring Hurung, Sanitra Sebangau Indah, Nepenthes spp., Sebangau National Park. 


\section{PENDAHULUAN}

Pandangan mengenai komunitas tidak hanya dengan cakupan wilayah yang luas dan populasi yang besar, namun pada area yang sangat kecil, seperti pada kantong Nepenthes spp [1,9]. Kantong ini adalah modifikasi daun, sebagai upaya untuk efisiensi tangkapan unsur hara yang dibawa oleh air hujan. Kantong Nepenthes spp. sebagai pemangsa yang pasif, namun dinamis Aktivasi perangkap kantong ini dipicu oleh tetesan air hujan pada peristome $[2,3,4]$

Beberapa penelitian terhadap serangga yang terperangkap dalam kantong Nepenthes spp., berkembang dan menunjukkan interaksi yang kompleks. [3]. Faktor yang mempengaruhi serangga yang terperangkap antara lain adalah nektar yang berada pada dinding kantong dan juga refleksi dari sinar UV aktif, menarik serangga untuk mendekat hingga akhirnya terjebak di dalam kantong Nepenthes gracillis [4]

Lebih lanjut, bentuk peristome dan warna kantong juga menjadi faktor yang menarik serangga. Serangga yang terperangkap pada kantong tiga jenis Nepenthes spp. yakniN. ampullaria, $N$. gracilis dan $N$. rafflesianamembentuk struktur komunitas mikro yang sangat kompleks [5]. Penelitian mempelajari komposisi takson tingkat suku serangga yang terprangkap dalam kantung Nepenthes spp. di Taman Nasional Sebangau, Kalimantan Tengah.

\section{METODE PENELITIAN}

Jenis penelitian - penelitian deskriptif kualitatif dengan metode survey= Penelitian ini merupakan upaya pengumpulan informasi dari sebagian populasi yang dianggap dapat mewakili populasi tertentu, untuk memperoleh fakta dari gejala yang ada dan mencari keterangan secara faktual dari suatu kelompok, daerah dan sebagainya. Survey ini biasanya digunakan untuk meneliti status suatu objek, suatu set kondisi, suatu sistem pemikiran ataupun suatu kelas peristiwa sekarang.

LokasiPenelitian - Penelitian ini akan dilaksanakan di area saluran Eks. PT
Sanitra Sebangau Indah (SSI), wilayah kerja Seksi Pengelolaan Taman Nasional (SPTN) wilayah II Pulang Pisau dan Habaring Hurung, wilayah kerja Seksi Pengelolaan Taman Nasional Wilayah I Kota Palangkaraya [7]

Survei (Linetransects) dan plot Penelitian dilakukan dengan menelusuri transek pada plot penelitian terdahulu. Transek penelusuran berjarak $1 \mathrm{~km}$. Penelusuran pada transek dilakukan dengan berjalan mengikuti jalur transek sambil melakukan pengamatan di kiri dan kanan transek untuk melihat kehadiran Nepenthes. Apabila ditemukan kehadiran Nepenthes, peneliti berhenti, untuk mengambil foto dan menuangkan cairan yang terdapat dalam cawan ke dalam plasticzip, memberi label plastik spesimen dan melakukan pencatatan data. Jika dalam garis transek, tidak ditemukan Nepenthes, maka dilakukan cuplikan purposif dengan membuat plot ukuran $2 \mathrm{x}$ $2 \mathrm{~m}$ di area kajian yang memiliki Nepenthes.

Spesimen Serangga - Keberadaan serangga dalam kantong menggunakan skala nominal; ada (1), tidak ada (2). Serangga yang diperoleh, dan disimpan dalam plastic-zip lockakan ditransportasi ke Laboratorium Zoologi, Universitas Palangkaraya untuk melakukan identifikasi. Identifikasi sedapat mungkin dilakukan sampai pada tingkat jenis, namun mengingat kondisi spesimen yang tidak utuh (dekomposisi oleh cairan kantong) maka hanyadilakukan sampai pada tingkat suku.

Teknik Analisis Data- Hasil pengumpulan data pada dua lokasi kajian, ditransportasi ke laboratorium untuk dilakukan identifikasi sampai tingkat suku. Hasil identifikasi dilakukan berjenjang dan ciri utama setiap suku dideskripsikan dan didokumentasi. Jika perlu, diberikan gambar pembanding dari literatur terkait.

\section{HASIL DAN PEMBAHASAN}

Ada empat jenis Nepenthes yang dijumpai pada lokasi kajian, yakni Nepenthes mirabilis, $N$. gracilis, $N$. rafflesiana, $N$. ampullaria.Tiga jenis yang disebutkan terlebih dahulu,memiliki dua 
kantong yaitu kantong bagian bawah berbentuk oval dan kantong bagian atas berbentuk silinder berwarna hijau, merah maroon atau terkadang kemerah-merahan. Kantong bagian bawah umumnya memliki dua sayap berupa duri - duri kecil yang berjajar ke atas, mulut bundar, penutup bundar dan memiliki taji.[5, 7, 12]. Sementara jenis yang disebut terakhir dijumpai bergerombol pada lantai hutan, tanpa penutup kantong $[7,8,12]$.

Pengamatan di Eks. Kanal PT Sanitra Sebangau Indah (SSI), difokuskan pada jenis N. Gracilis, sedangkanpada lokasi Habaring hurung, dideskripsikan per jenis kantung Nepenthes spp. yang dijumpai di lokasi kajian.

Tabel 1. Rekapitulasi Suku Serangga yang Terperangkap dalam Kantong Nepenthes spp. di dua lokasi kajian

\begin{tabular}{|c|c|c|c|c|c|c|c|c|}
\hline \multirow{2}{*}{$\begin{array}{l}\text { KELOMPOK } \\
\text { TAKSON }\end{array}$} & \multicolumn{4}{|c|}{ SSI } & \multicolumn{4}{|c|}{ HAB HUR } \\
\hline & 1 & 2 & 3 & 4 & 1 & 2 & 3 & 4 \\
\hline $\begin{array}{l}\text { Formicidae } \\
\text { (Semut) }\end{array}$ & & & & & & & & \\
\hline $\begin{array}{l}\text { Tephritidae (Lalat } \\
\text { Buah) }\end{array}$ & & & & & & & & \\
\hline $\begin{array}{l}\text { Culicidae } \\
\text { (Nyamuk) }\end{array}$ & & & & & & & & \\
\hline $\begin{array}{l}\text { Geometridae } \\
\text { (Ngengat Sayap } \\
\text { Gelombang) }\end{array}$ & & & & & & & & \\
\hline $\begin{array}{l}\text { Heliconidae (Kupu- } \\
\text { kupu) }\end{array}$ & & & & & & & & \\
\hline $\begin{array}{l}\text { Nitidulidae } \\
\text { (Kumbang tanah } \\
\text { kecil) }\end{array}$ & & & & & & & & \\
\hline $\begin{array}{l}\text { Cynipidae (Tawon } \\
\text { penggali gall) }\end{array}$ & & & & & & & & \\
\hline $\begin{array}{l}\text { Thomisidae (Laba- } \\
\text { laba kepiting) }\end{array}$ & & & & & & & & \\
\hline Culicidae (Lalat) & & & & & & & & \\
\hline $\begin{array}{l}\text { Liparidae } \\
\text { (Ngengat) }\end{array}$ & & & & & & & & \\
\hline $\begin{array}{l}\text { Chrysomelidae } \\
\text { (Kumbang) }\end{array}$ & & & & & & & & \\
\hline Flatidae (Wereng) & & & & & & & & \\
\hline $\begin{array}{l}\text { Curculionidae } \\
\text { (Kumbang } \\
\text { Moncong) }\end{array}$ & & & & & & & & \\
\hline $\begin{array}{l}\text { Cucucidae } \\
\text { (Kumbang) }\end{array}$ & & & & & & & & \\
\hline $\begin{array}{l}\text { Dysticidae } \\
\text { (Kumbang } \\
\text { Gelembung) }\end{array}$ & & & & & & & & \\
\hline
\end{tabular}

Keterangan :

SSI : Wilayah Kanal Eks. PT Sanitra Sebangau Indah

HAB HUR: Wilayah Habaring Hurung

I, II, III dan IV : Jumlah transek

Delapan suku tersebut menunjukkan keragaman serangga yang terperangkap dalam kantong Nepenthes gracillis di area Kanal Eks PT. SSI Taman Nasional Sebangau dengan persentase suku yang sering dijumpai yaitu suku Formicidae dan suku Culicidae [5]. Tabulasi data suku serangga yang terperangkapdalam kantong Nepenthes gracillis dapat dilihat dalam Tabel 1.

Serangga yang terperangkap dalam kantong Nepenthes gracillis yang ditemukan selama penelitian di area Kanal Eks PT. SSI Taman Nasional Sebangau adalah sebanyak 8 suku serangga, yaitu: Suku Nitidulidae, Formicidae, Cynipidae, Thomisidae, Culicidae, Chrysomelidae, Flatidae dan Tropiduchidae. Sementara di lokasi Habaring Hurung, dijumpai sembilan suku, yakni Formicidae, Tephritidae, Culicidae, Geometridae, Heliconidae, Liparidae, Curculionidae, Culicidae dan Dysticidae [6, 10, 11].

Hasil pengamatan serangga secara utuh dan fragmen yang terperangkap dalam kantong Nepenthes mirabilis pada transek 1 disajikan dalam Gambar 1, berikut ini.
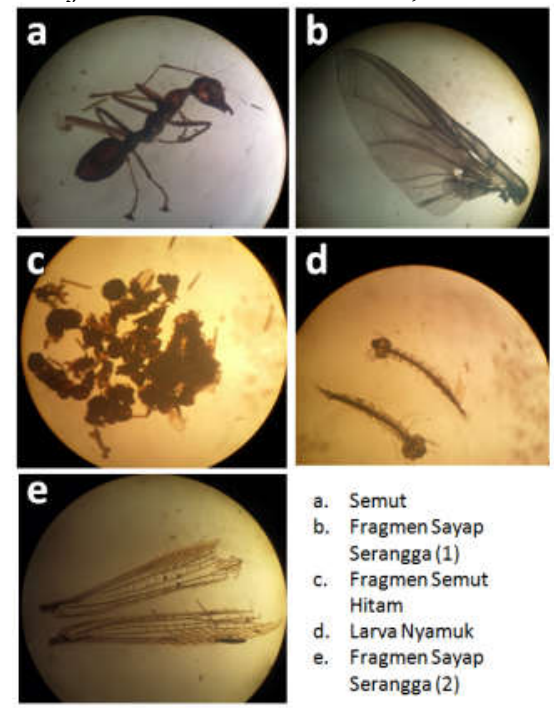

Gambar 1. Serangga dan Fragmen yang Terperangkap dalam Kantong Nepenthes mirabilis pada Transek 1 
Berdasarkan hasil pengamatan tersebut diketahui 2 spesimen termasuk ke dalam suku Formicidae terdiri dari semut merah (1.a) dan kumpulan fragmen semut hitam (17.c); 1 spesimen termasuk ke dalam suku Tephritidae yang merupakan sayap lalat buah Bactrocera sp. (1.b); 1 spesimen termasuk ke dalam suku Culicidae yang merupakan larva nyamuk (1.d); dan 1 spesimen (1.e) yang merupakan fragmen sayap serangga belum teridentifikasi. Hewan lain selain serangga juga terperangkap dalam kantong Nepenthes mirabilis pada transek 1 yang disajikan dalam Gambar 2.

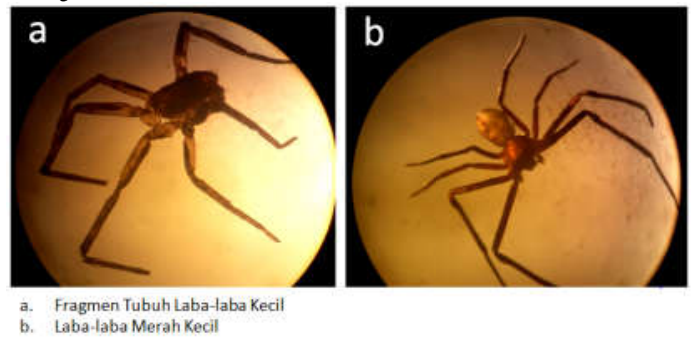

Gambar 2. Hewan Lain yang Terperangkap dalam Kantong Nepenthes mirabilis pada Transek 1

Hasil pengamatan diketahui kedua spesimen di atas (2.a dan 2.b) merupakan jenis laba-laba dari suku Thomicidae. Nepenthes mirabilis tidak hanya ditemukan pada transek 1, tetapi juga pada transek 2, 3 dan 4. Spesimen serangga, fragmen dan hewan lain yang terperangkap diketahui termasuk ke dalam suku yang sama seperti yang ditemukan dalam kantong Nepenthes mirabilis pada transek 1. Serangga-serangga tersebut adalah semut (Formicidae), nyamuk (Culicidae), lalat buah (Tephritidae) dan beberapa fragmen serangga yang belum teridentifikasi $[6,10]$.

Takson serangga yang teridentifikasi dalam kantong Nepenthes mirabilis didominasi oleh semut dari suku Formicidae. Semut ditemukan di setiap kantong Nepenthes mirabilis pada transek 1, 2, 3 dan 4 dengan populasi yang cukup banyak, hal ini dikarenakan semut merupakan hewan yang hidup berkoloni dan mencari makan secara bersama-sama. Semut selalu mencari makan bersamasama, jadi saat seekor semut terperangkap dalam kantong Nepenthes karena tertarik pada nektar yang dihasilkannya, semutsemut yang lain akan mengikuti [3].

Kemudian, hasil pengamatan serangga secara utuh dan fragmen yang terperangkap dalam kantong Nepenthes gracilis pada transek 1 disajikan dalam Gambar 3 berikut ini.
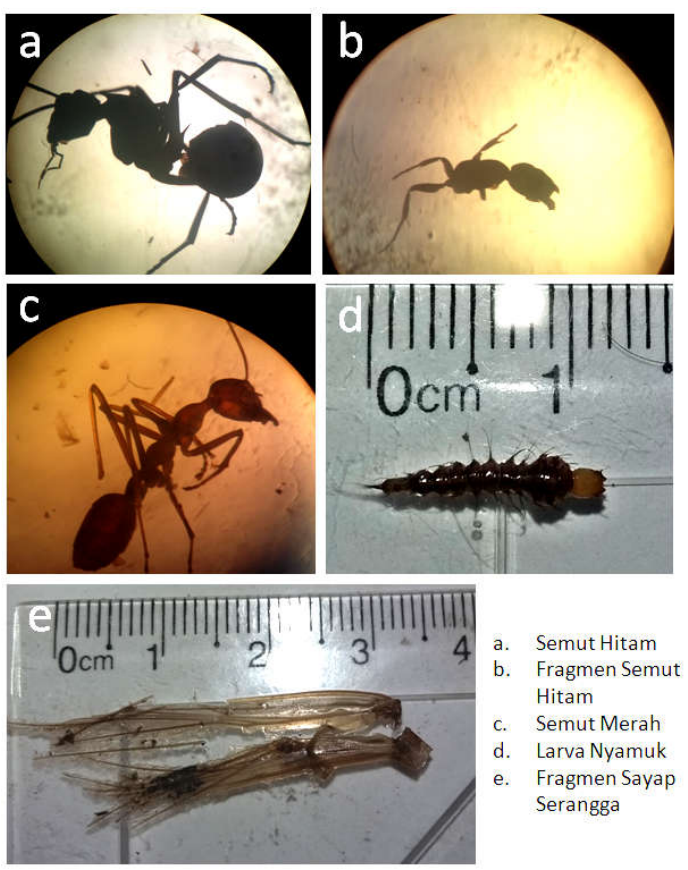

Gambar 3. Serangga dan Fragmen yang Terperangkap dalam Kantong Nepenthes gracilis pada Transek 1

Gambar 3 di atas menunjukkan hasil pengamatan serangga dan fragmen serangga yang terperangkap dalam kantong Nepenthes gracilis pada transek 1 menggunakan mikroskop stereo dengan 20 kali perbesaran dan untuk serangga atau fragmen yang berukuran besar diukur menggunakan mistar. Berdasarkan hasil pengamatan tersebut diketahui 3 spesimen termasuk ke dalam suku Formicidae terdiri dari semut hitam (3.a), fragmen semut hitam (3.b) dan semut merah (3.c); 1 spesimen termasuk ke dalam suku Culicidae yang merupakan larva nyamuk (3.d),dan 1 spesimen (3.e) yang merupakan fragmen sayap serangga belum teridentiikasi. Nepenthes gracilis ditemukan pada transek 1, 2, 3 dan 4, sebagian besar serangga yang ditemukan pada setiap kantongnya termasuk ke dalam suku yang sama, seperti semut (Formicidae) dan nyamuk (Culicidae). Hasil pengamatan serangga yang 
terperangkap dalam kantong Nepenthes gracilis pada transek 2 dapat dilihat pada Gambar 4 berikut ini.
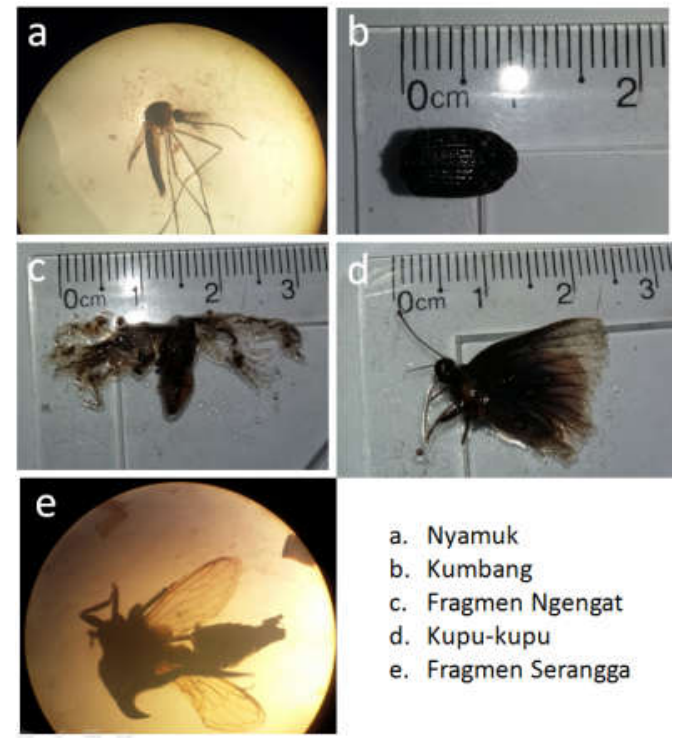

a. Nyamuk

b. Kumbang

c. Fragmen Ngengat

d. Kupu-kupu

e. Fragmen Serangga

Gambar 4. Serangga yang Terperangkap dalam Kantong Nepenthes gracilis pada transek 2

Gambar di atas menunjukkan hasil pengamatan serangga-serangga yang terperangkap dalam kantong Nepenthes gracilis pada transek 2 menggunakan mikroskop stereo dan untuk serangga atau fragmen yang berukuran besar diukur menggunakan mistar. Berdasarkan hasil pengamatan tersebut diketahui 1 spesimen (4.a) merupakan seekor nyamuk termasuk ke dalam suku Culicidae; 1 spesimen (4.b) merupakan seekor kumbang yang tidak teridentifikasi; 2 spesimen termasuk ke dalam ordo Lepidoptera terdiri dari ngengat (4.c, Geometridae) dan kupu-kupu (4.d, Heliconidae); dan 1 spesimen yang merupakan fragmen tubuh serangga yang belum teridentifikasi.

Jenis serangga yang terperangkap dalam kantong Nepenthes gracilis pada transek 3 dan 4 terdiri dari seranggaserangga yang termasuk ke dalam suku yang sama seperti yang ditemukan dalam kantong Nepenthes gracilis pada transek 1 dan 2. Serangga-serangga tersebut adalah semut (Formicidae), nyamuk (Culicidae), ngengat (Geometridae),kupu-kupu (Heliconidae), kumbang dan beberapa fragmen tubuh serangga yang belum teridentifikasi [6,10]. Gambar 5 menunjukkan hewan arthropoda selain serangga yang terperangkap dalam kantong Nepenthes gracilis pada transek 1 di bawah mikroskop stereo dengan 20 kali perbesaran. Spesimen tersebut merupakan fragmen tubuh laba-laba (5.a) dan seekor laba-laba utuh (5.b), setelah diidentifikasi diketahui termasuk ke dalam suku Thomisidae.

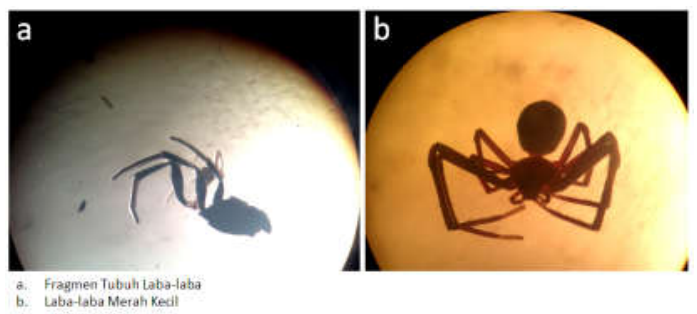

Gambar 5. Hewan Lain yang Terperangkap dalam Kantong Nepenthes gracilis

Lebih lanjut, hasil pengamatan serangga secara utuh dan fragmen yang terperangkap dalam kantong Nepenthes rafflesiana pada transek 1 disajikan dalam Gambar 6 berikut ini.

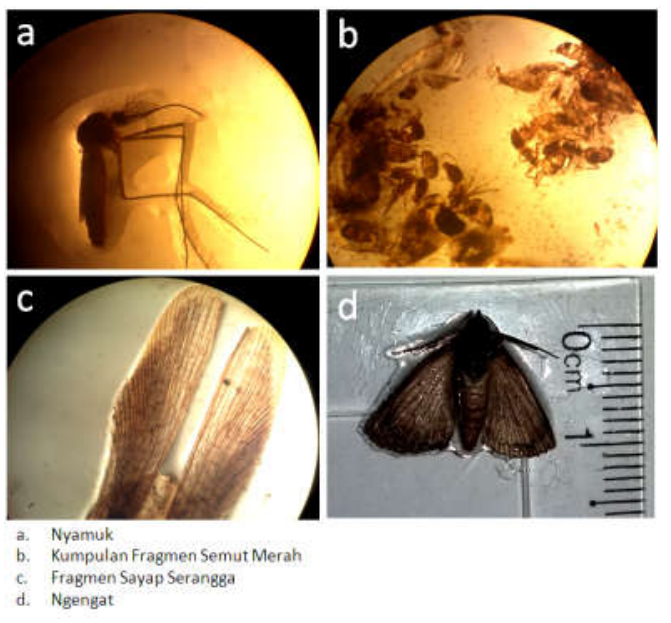

Gambar 6. Serangga yang Terperangkap dalam Kantong Nepenthes rafflesiana pada Transek 1

Gambar 6 di atas merupakan hasil pengamatan serangga dan fragmen serangga yang terperangkap dalam kantong Nepenthes rafflesiana pada transek 1 menggunakan mikroskop stereo dan untuk serangga atau fragmen yang berukuran besar diukur menggunakan mistar.Berdasarkan hasil pengamatan tersebut diketahui 1 spesimen (6.a) merupakan seekornyamuk yang termasuk ke dalam suku Culicidae; 1spesimen (6.b) merupakan kumpulan fragmen semut 
merah yang termasuk ke dalam suku Formicidae; 1 spesimen (6.d) merupakan seekor ngengat yang termasuk ke dalam suku Liparidae; dan 1 spesimen (6.c) merupakan fragmen sayap serangga yang belum teridentifikasi.

Nepenthes rafflesiana juga ditemukan pada transek 3 dan 4 yang di dalam kantongnya terperangkap seranggaserangga yang sebagian besar sama seperti yang ditemukan dalam kantong Nepenthes rafflesiana pada transek 1. Seranggaserangga tersebut adalah nyamuk (Culicidae), semut (Formicidae), ngengat (Liparidae) dan fragmen sayap serangga serta fragmen tubuh serangga yang belum teridentifikasi. Selain serangga-serangga tersebut, pada transek 3 dan 4 juga ditemukan jenis serangga lain seperti kumbang dari suku Curculionidae, fragmen sayap ngengat dari suku Liparidae dan fragmen serangga yang tidak diketahui jenisnya (Gambar 7).

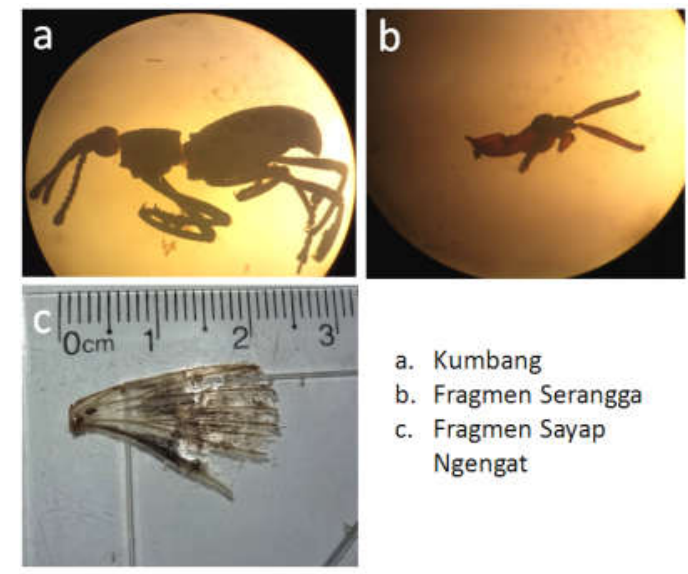

Gambar 7. Serangga Lainnya yang Terperangkap dalam Kantong Nepenthes rafflesiana pada Transek 3 dan 4

Hewan arthropoda lain juga ditemukan terperangkap dalam kantong Nepenthes rafflesiana. Hasil pengamatan hewan arthropoda lain tersebut dapat dilihat pada Gambar 24 berikut.

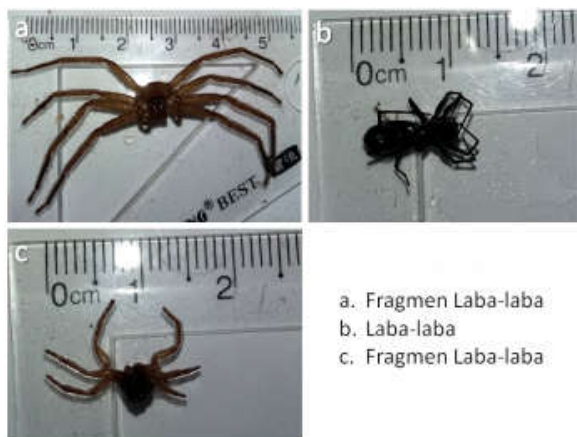

Gambar 8. Hewan Arthropoda Lain yang Terperangkap dalam Kantong Nepenthes rafflesiana

Berdasarkan hasil pengamatan hewan arthropoda lain yang ditunjukkan oleh Gambar 8 di atas diketahui 2 spesimen (8.a dan 8.c) merupakan fragmen laba-laba dan 1 spesimen (8.b) seekor laba-laba utuh yang ketiganya termasuk ke dalam suku Thomisidae [11].Pengamatanpada kantung Nepenthes ampullaria hanya ditemukan pada transek 5 dan 6 . Hasil pengamatan serangga secara utuh dan fragmen yang terperangkap dalam kantong Nepenthes ampullaria disajikan dalam Gambar 9 berikut ini.

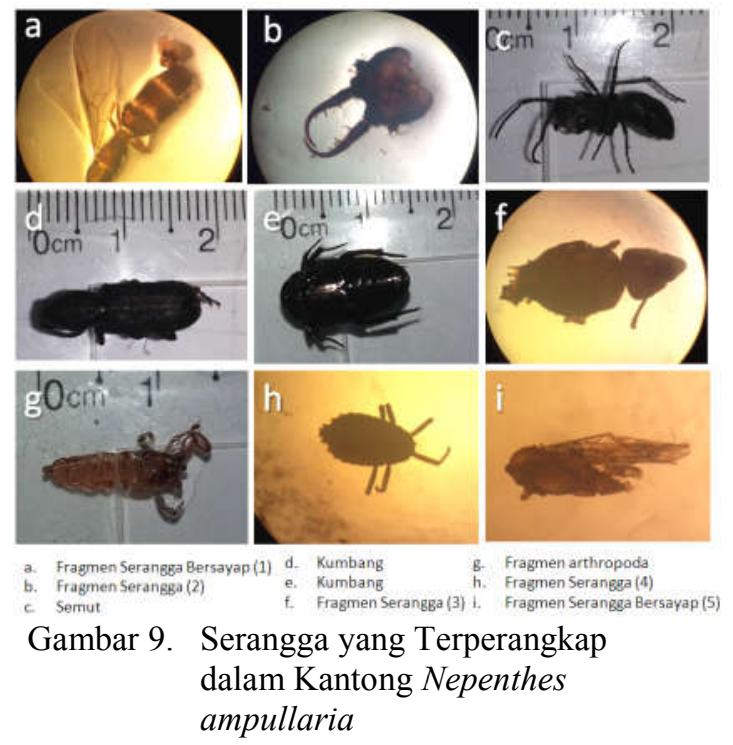

Informasi yang didapat dari hasil pengamatan di atas adalah 6 spesimen (9.a, 9.b, 9.f, 9 g, 9.h dan 9.i) yang merupakan fragmen serangga berupa cepal, thorax dan abdomen belum teridentifikasi; 2 spesimen merupakan dua ekor serangga yang masing-masing termasuk ke dalam suku Cucujidae (9.d) dan Dystiscidae (9.e); dan 1 spesimen (9.c) merupakan seekor semut yang 
termasuk ke dalam suku Formicidae $[6,10]$. Nepenthes ampullaria biasanya ditemukan tumbuh di tempat dengan kanopi tertutup, karena jenis ini selain menangkap serangga dan hewan arthropoda lain juga memerlukan serasah daun. Berdasarkan hasil pengamatan, ditemukan hewan arthropoda lain selain serangga, berudu berkaki, bagian generatif tumbuhan dan serasah daun (Gambar 10).

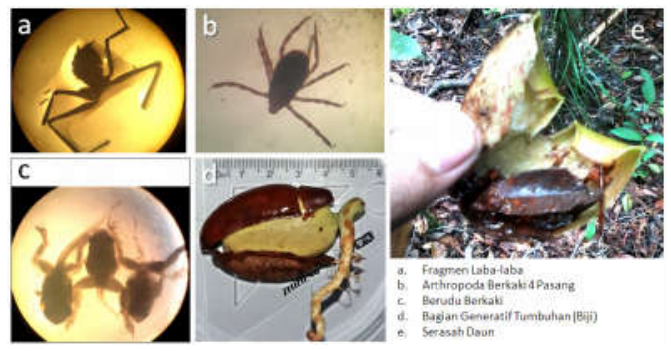

Gambar 10. Hewan dan Bagian Tumbuhan yang Terperangkap dalam Kantong Nepenthes ampullaria

\section{KESIMPULAN}

Berdasarkan hasil analisis terhadap data penelitian, maka dapat disimpulkan bahwa takson tingkat suku serangga yang terperangkap dalam Kantong Nepenthes yang ditemukan selama penelitian di Resort Habaring Hurung, adalah sebanyak sembilan takson suku serangga. Sementara itu di area Kanal Eks PT. SSI Taman Nasional Sebangau menunjukkan delapan takson suku serangga. Takson suku yang secara konsisten dijumpai hamper di seluruh specimen kantung pada dua lokasi kajian adalah dari kelompok takson suku Formicidae (Semut), Culicidae (Nyamuk) dan Thormisidae (Laba-laba kepiting).

\section{UCAPAN TERIMA KASIH}

Penulis mengucapkan terima kasih kepada Balai Taman Nasional atas ijin pengambilan data di dua wilayah kerja. Terima kasih kepada Lembaga Penelitian UPR melalui DIPA PNBP Universitas Palangkaraya dengan penugasan nomor 2899/UN24/PL/2016, tanggal 19 Agustus 2016.

\section{DAFTAR PUSTAKA}

[1] Campbell, N.A., Reece, J.B., Urry, L.A., Cain, M.L., Wasserman, S.A.,
Minorsky, P.V., \& Jackson, R.B. 2008. Biologi. Edisi Kedelapan Jilid 3. Jakarta : Penerbit Erlangga.

[2] Bauer, U., Grafe, T.U., Federle, W. 2011. Evidence For Alternative Trapping Strategies In Two Forms Of The Pitcher Plant, Nepenthes Rafflesiana. J. Exp. Bot 62:36833692.

[3] Bauer U, Scharmann M, Skepper J, Federle W. 2013 'Insect aquaplaning' on a superhydrophilic hairy surface: how Heliamphora nutans Benth. pitcher plants capture prey. Proc R Soc B 280: 20122569. http://dx.doi.org/10.1098/rspb.2012. $\underline{2569}$

[4] Hua, Y. \& Lee, H. 2005. Food Web and Fluid in Pitchers of Nepenthes mirabilis in Zhuhai China. Acta Botanica Gallica 152 (2): 165-175

[5] Moran, Jonathan A., Webber E. Booth dan Joseph K. Charles. 2011. Aspects of Pitcher morphology and spectral chracteristics of six Bornean Nepenthes Pitcher plants : Implications for prey capture. Annals of Botany83: 521 - 528 .

[6] Bittleston, Leonora S., Christopher C. M. Baker, Lila B. Strominger, Anne Pringle dan Naomi E. Pierce, 2015. Metabarcoding as a tool for investigating arthropod diversity in Nepenthes pitcher plants. Austral Ecology. doi:10.1111/aec.12271.

[7] Shepherd, P.A., Rieley, J.O., Page, S.E. 1997. The Relationship between forest vegetation and peat characteristics in the upper catchment of Sungai Sebangau, Central Kalimantan. In: Rieley JO, Page SE (eds) Tropical peatlands. Samara Publishing Limited, Cardigan.

[8] Arifin, H. 2012. Studi Keragaman Jenis Kantong Semar di Area Eks Kanal PT. Sanitra Sebangau Indah Taman Nasional Sebangau. Skripsi. 
Tidak diterbitkan, Palangka Raya :

Fakultas Keguruan dan Ilmu

Pendidikan, Jurusan P.MIPA.

[9] Krebs, C.J. 1978. Ecology. The

Experimental Analysis of

Distribution and Abundance.

Second Edition. Harper and Row, New York. 678 pp.

[10] Borror D.J., White, Richard E. 1970. Insects. Hugthon Mifflin Company, New York.

[11] Christina, L.,S. 1991. Kunci Determinasi Serangga. Kanisius. Yogyakarta.

[12] Mansur, M., 2007. Keragaman jenis Nepenthes (Kantong Semar) Dataran Rendah di Kalimantan. Berita Biologi 8(5), 2007 p. 335 341. 